\title{
Multi-material 3D bioprinting of porous constructs for cartilage regeneration
}

Authors:

Laura Ruiz-Cantua,b, Andrew Gleadall ${ }^{\mathrm{c}}$, Callum Faris ${ }^{\mathrm{d}}$, Joel Segal ${ }^{\mathrm{e}}$, Kevin Shakesheff ${ }^{\mathrm{b}}$ and Jing Yang ${ }^{\text {b\# }}$

Institutions:

a. Centre for Additive Manufacturing, Faculty of Engineering, University of Nottingham, University Park, Nottingham, NG7 2RD, UK

b. Regenerative Medicine and Cellular Therapies Division, Faculty of Science, University of Nottingham, University Park, Nottingham, NG7 2RD, UK

c. Wolfson School of Mechanical, Electrical and Manufacturing Engineering, University of Loughborough, Loughborough, LE113TU.

d. Department of Otorhinolaryngology and Facial Plastic Reconstructive Surgery, Poole Hospital, Poole, BH15 2JB, UK

e. Advanced Manufacturing Technology Research Group, Faculty of Engineering, University of Nottingham, University Park, Nottingham, NG7 2RD, UK

\# Corresponding Author / E-mail: jing.yang@nottingham.ac.uk

\section{Abstract}

The current gold standard for nasal reconstruction after rhinectomy or severe trauma includes transposition of autologous cartilage grafts in conjunction with coverage using an autologous skin flap. Harvesting autologous cartilage requires a major additional procedure that may create donor site morbidity. Major nasal reconstruction also requires sculpting autologous cartilages to form a cartilage framework, which is complex, highly skill-demanding and very time consuming. These limitations have prompted facial reconstructive surgeons to explore different techniques such as tissue engineered cartilage. This work explores the use of multi-material 3D bioprinting with chondrocyte-laden gelatin methacrylate (GeIMA) and polycaprolactone (PCL) to fabricate constructs that can potentially be used for nasal reconstruction. In this study, we have investigated the effect of 3D manufacturing parameters including temperature, needle gauge, UV exposure time, and cell carrier formulation (GelMA) on the viability and functionality of chondrocytes in bioprinted constructs. Furthermore, we printed chondrocyte-laden GeIMA and PCL into composite constructs to combine biological and mechanical properties. It was found that $20 \% \mathrm{w} / \mathrm{v}$ GeIMA was the best concentration for the 3D bioprinting of the chondrocytes without comprising the scaffold's porous structure and cell functionality. In addition, the 3D bioprinted constructs showed neocartilage formation and similar 
mechanical properties to nasal alar cartilage after a 50-day culture period. Neocartilage formation was also observed in the composite constructs evidenced by the presence of glycosaminoglycans and collagen type II. This study shows the feasibility of manufacturing neocartilage using chondrocytes/GelMA/PCL 3D bioprinted porous constructs which could be applied as a method for fabricating implants for nose reconstruction.

Key words:

Tissue engineering, cartilage, chondrocytes, bioprinting, 3D printing, surface porosity, polycaprolactone, GeIMA, multi-material 3D printing.

\section{Introduction}

3D printing can potentially benefit plastic and reconstructive surgeries by fabricating patient-specific tissue replacements with tissue-like functions and mechanical properties. One specific example in the field of plastic and reconstructive surgery is nasal reconstruction. The nose is the most identifiable feature that defines the human face. Deformities caused by trauma, cancer surgery and malformations can have adverse physical and psychological effects on the patients [1]. The nose is comprised of hyaline cartilage, fibro-fatty tissues, internal nasal lining and skin [2]. The current surgical approach for major nose reconstruction is a complex and time-consuming procedure that involves harvesting rib cartilage, and manually carving and suturing them into a nose-shaped framework. Shaping harvested rib cartilage into a nose-shaped framework is highly skill demanding, which requires prolonged training to perfect. Once completed the framework is then covered by autologous skin and mucosa inner nasal lining [3]. Due to the complexity of the surgical procedure, the duration of the operation can exceed 8 hours, during which time the patient is under general anaesthesia [4]. In addition, harvesting large amounts of rib cartilage is associated with postoperative chest wall deformities, high levels of postoperative pain and the risk of iatrogenic pneumothorax. These drawbacks of the current approach for major nasal reconstruction fuelled the interests from facial plastic and reconstructive surgeons in finding tissue engineered nasal replacements.

Since the seminal work on tissue engineered ear-shaped cartilage using polymer scaffolds seeded with chondrocytes [5], a body of work has been carried out to fabricate a tissue engineered ear [6],[7] or nose [8]. A recent first-in-man trial has utilised autologous chondrocyte-seeded collagen sheet for repairing the nose alar lobule after excision of non-melanoma skin cancer. The results from this study showed that the tissue engineered constructs formed fibrocartilage in vitro and generated satisfactory functional outcomes after one-year implantation, despite the fact that the fibrocartilage was remodelled into fibromuscular fatty tissues [9]. This is a very encouraging advancement towards the use of tissue engineered constructs in nose reconstruction. However, the mechanical properties of the engineered nasal tissue need to be increased in order to use them in major nasal reconstructions. 
$3 \mathrm{D}$ bioprinting is emerging as an alternative approach for fabricating patient-specific nose/ear constructs suitable for implantation. Compared to conventional scaffold fabrication methods, 3D bioprinting can fabricate patient-specific scaffolds/constructs with controlled architectures without moulding. In addition, cells can be printed within the scaffolds/constructs with much better spatial precision compared to cell seeding into porous scaffolds. Nose-shaped hydrogel constructs have been made using bioprinting of chondrocyte-laden alginate/gellan. The study showed high shape fidelity of the bioprinted constructs, and the secretion of cartilage-related matrices during in vitro cultivation. One limitation was that the cells within the central region of constructs showed reduced viability due to insufficient mass transportation. In addition, the mechanical strength of the hydrogel was lower than septal cartilage due to the inherent low mechanical properties of hydrogels [10]. Another study has employed a multi-material approach to improve mechanical stability and the transportation of nutrients and oxygen. In this approach materials that promote cartilage regeneration and offer mechanical support, respectively, were combined to form 3D composite structures. The composite structure consisted of a cell-laden blend hydrogel containing gelatin, fibrinogen, hyaluronic acid and glycerol which was co-printed with PCL and Pluronic F-127 to form an earshaped construct. Micro channels were incorporated within the structure in order to enhance nutrients and oxygen transport [11]. After crosslinking of fibrinogen using thrombin post printing, the uncrosslinked components (gelatin, HA, glycerol and Pluronic F-127) were removed. Although the work was a significant advance in bioprinting tissues with clinically relevant sizes, the hydrogel blend was complex, which may hinder its clinical translation. The employment of a hydrogel that crosslinks during printing and does not need any sacrificial material will reduce fabrication time and the complexity of the final constructs, hence a significant advance for the translation of bioprinted tissues to the clinic.

The promising multi-material bioprinting approach [12-14] has encouraged us to fabricate noseshaped cartilaginous constructs for nasal reconstruction. In our previous work we have demonstrated the ability to create personalised 3D nose-shaped scaffolds with controlled surface porosity using PCL [15]. Following this work, here we investigated the multi-material 3D bioprinting with PCL and chondrocyte-laden GelMA for fabricating nasal cartilage. We used the hydrogel GeIMA as a cell carrier, due to its desirable characteristics such as biocompatibility [16], biodegradability [17], limited antigenicity [18] and fast crosslinking using UV light. A multi-material printing process with acellular GeIMA/Hyaluronic acid and PCL has been previously reported by Schuurman et al [19]. In that study PCL was used simply as a mould to confine the GelMA/Hyaluronic acid mixture in place. Hyaluronic acid was used to increase the viscosity of GeIMA to make it printable. The difference of our work is that the thermo-responsive property of GeIMA is utilised to increase viscosity, facilitate printability and create self-supporting strands without the need of adding excipients or supportive moulds. Additionally, the use of GeIMA allowed the incorporation of interconnected pores within the structure. PCL was used to give structural support and mechanical stability to the entire construct. Our 
approach simplifies the material system, hence benefiting the subsequent clinical translation of the bioprinted tissues.

Here, we first evaluated the effect of the 3D printing process parameters including printing temperature, needle gauge and UV exposure on the viability and genotoxicity of chondrocytes. Subsequently, cell proliferation, cartilage ECM secretion and mechanical properties of the 3D bioprinted porous cell-laden GelMA were quantified. Lastly, cell-laden GelMA/PCL porous constructs were bioprinted and their in vitro performance was studied for 21 days. Collectively, the results have demonstrated the proof of concept of employing multi-material bioprinting to fabricate tissue replacements for nasal reconstructive surgeries.

\section{Materials and methods}

\subsection{Preparation of GelMA}

GeIMA was prepared as previously described by Van Den Bulcke et al [16]. Briefly, a 10\% gelatin solution (skin porcine gelatin type A G2500, Sigma-Aldrich) was prepared in phosphate buffer saline ( $0.01 \mathrm{M} \mathrm{P4417,} \mathrm{Sigma-Aldrich)} \mathrm{at} 50^{\circ} \mathrm{C}$. After an hour, $8 \mathrm{ml}$ of methacrylic anhydride (276685 SigmaAldrich) was added dropwise at a speed of $0.5 \mathrm{ml} / \mathrm{min}$ to the gelatin solution and allowed to react for 3 hours at $50^{\circ} \mathrm{C}$. To stop the reaction, the solution was diluted $5 \mathrm{X}$ with warm phosphate buffer solution (PBS). In order to remove any unreacted methacrylic anhydride, the mixture was dialysed against distilled water using $80 \mathrm{kDa}$ dialysis membranes for 1 week. The final solution was freezedried for 7 days and stored at $-80^{\circ} \mathrm{C}$.

\subsection{Rheological testing}

GeIMA $10 \%, 15 \%$ and $20 \%$ solutions were prepared by dissolving the required amount of polymer in a-MEM (12-169F, Lonza). After GelMA was fully dissolved, the photo initiator Irgacure 2959 was added at a concentration of $0.5 \% \mathrm{w} / \mathrm{v}$.

Rheological evaluation was performed on a MCR rheometer (Anton-Paar). To evaluate the viscosity of different concentrations of GelMA a $25 \mathrm{~mm}$ diameter parallel plate was used with a gap of $0.5 \mathrm{~mm}$. The viscosity was measure at each temperature while the gels were subjected to a temperature decrease ramp in the range of $37-15^{\circ} \mathrm{C}$ with a decrease rate of $5^{\circ} \mathrm{C} / \mathrm{min}$ at a constant shear rate of $100(1 / \mathrm{s})$. All measurements were conducted in triplicates. To determine the time needed to crosslink GeIMA, $200 \mu \mathrm{l}$ of the different GelMA concentrations were added on the rheometer and exposed to UV light for a range of time from 10-30 seconds using the UV lamp Omnicure Series 1000 (Lumen 
Dynamics). The complex modulus was measured after UV crosslinking using an $8 \mathrm{~mm}$ diameter plate at a frequency of $1 \mathrm{~Hz}$.

\subsection{Chondrocytes isolation and expansion}

Cartilage tissue was harvested from sheep condyle. The cartilage was shaved from the condyle using a scalpel and immersed in PBS containing 5\% antibiotics/antimycotics. The cartilage slices were then washed three times with the same solution in order to remove any remaining blood. Afterwards, the slices were cut into $2 \mathrm{~mm}^{2}$ pieces. Chondrocytes were isolated through an enzymatic digestion by immersing the cartilage pieces in an a-MEM (12-169F, Lonza) solution containing $0.2 \%$ collagenase type II (234155, Sigma-Aldrich) for 4 hours. After the cartilage pieces were completely digested, the solution was passed through a $70 \mu \mathrm{m}$ nylon strainer and centrifuged at $700 \times \mathrm{g}$ for 5 minutes. Isolated cells were plated in T75 flasks and cultured with a-MEM (12-169F, Lonza) supplemented with $5 \%(\mathrm{v} / \mathrm{v})$ foetal calf serum, 1\% MEM non-essential amino acids solution (M7145, Sigma-Aldrich), $1 \%$ antibiotics/antimycotics, $1 \%$ L-glutamine (25030081, Gibco) $0.025 \mathrm{~g} / \mathrm{ml}$ of ascorbic acid (A92902, Sigma-Aldrich), 10 ng/mL TGF- $\beta-1$ (T7039, Scientific laboratories supplies Ltd) and $5 \mathrm{ng} / \mathrm{mL}$ FGF-2 (SRP4037, Sigma-Aldrich). Cells passage 1 were used for viability studies and $3 \mathrm{D}$ bioprinting experiments.

\subsection{Viability and genotoxicity studies}

Cell viability was assessed separately on each step of the printing process. All the viability studies were performed $n=5$. The assessment was performed using LIVE/DEAD cell viability assay (L3224, Thermo Fisher Scientific) following the manufacturer's instructions. In brief, $4 \mu \mathrm{M}$ calcein-AM and 8 $\mu \mathrm{M}$ ethidium homodimer-1 (EthD-1) were prepared in media and added to the cell-laden print constructs and incubated at $37^{\circ} \mathrm{C}$ for $1 \mathrm{~h}$. Live cells stained by calcein-AM were imaged as green, and dead cells stained by EthD-1 were imaged as red using a fluorescence microscope. LIVE/DEAD and microscopy were selected for the analysis of cell viability because they are not dependant on the diffusion of reactants out of the hydrogel for quantification. The number of green/red cells were quantified using a fluorescence microscope and the ImageJ software. For the evaluation of the cells encapsulated inside the hydrogel, six different planes in the $z$ direction were imaged and quantified. Cell proliferation was evaluated by DNA quantification. The cells were released from the gels by papain digestion overnight. DNA was quantified using Quant-i ${ }^{\mathrm{T}} \mathrm{M}$ PicoGreen $®$ dsDNA Assay Kit (P7589, Thermo Fisher Scientific) according to the manufacturer instructions.

Genotoxicity of UV cells was evaluated based on a previous study [20]. Briefly, chondrocytes were seeded at a density of $10 \times 10^{5}$ cells/well, exposed and to UV light for 10,60, 150 and 600 seconds with Omnicure s1000 lamp at $2 \%$ power. After exposition, the cells were incubated for 24 hours at 
$37^{\circ} \mathrm{C}$ and $5 \% \mathrm{CO}_{2}$. Media was removed and cells were washed with PBS before fixing them with $1 \%$ paraformaldehyde at $0^{\circ} \mathrm{C}$ for 15 minutes. Following fixation, cells were immersed in $70 \%$ ethanol for 20 hours at $-20^{\circ} \mathrm{C}$. Then, cells were washed twice in PBS and immersed in $0.2 \%$ Triton-X-100/PBS $1 \%$ for 30 minutes. Cells were incubated overnight in $1 \%$ BSA containing $5 \mu \mathrm{g} / \mathrm{ml}$ mouse antivertebrates phosphor-histone monoclonal antibody Ser139 (05636, Merck Millipore, UK) at $4^{\circ} \mathrm{C}$. This was followed by another wash with PBS and incubation with Alexa Fluor 488 goat anti-mouse lgG conjugated secondary antibody (1:200) (ab150113, Abcam) for 30 minutes at room temperature. Finally, cells were co-stained with Hoechst $332581 \mu / \mathrm{ml}$ (861495, Sigma-Aldrich) for 15 minutes. Samples were imaged under the fluorescent microscope (Leica DM IRB).

\subsection{D printing and cell culture of GelMA/chondrocytes constructs}

GeIMA $10 \%, 15 \%$ and $20 \%$ hydrogels were prepared by dissolving the required amount of polymer in a-MEM). After GelMA was fully dissolved, the photo initiator Irgacure 2959 was added at a concentration of $0.5 \% \mathrm{w} / \mathrm{v}$. The polymer solutions were briefly vortexed and sterile filtered before use.

Passage 1 chondrocytes were detached using trypsin EDTA, centrifuged at $700 \times \mathrm{g}$ for 5 min and resuspended in GelMA at a concentration of $10 \times 10^{6} \mathrm{cells} / \mathrm{ml}$. The solution was transferred to the printing cartridge and gel at $20^{\circ} \mathrm{C}$ in the cooling chamber for 10 minutes. The scaffolds were designed in a square shape with overall dimensions of $5 \mathrm{~mm} \times 5 \mathrm{~mm}$. GelMA/chondrocytes were printed at a speed of $10 \mathrm{~mm} / \mathrm{s}$ using the REGENHU 3D Discovery Bioprinter. The spacing between the strands was $400 \mu \mathrm{m}$ and samples were printed using a tapered needle G27. Samples were cross linked for 20 seconds under UV and transferred to well plates containing a-MEM (12-169F, Lonza) supplemented with $5 \%(\mathrm{v} / \mathrm{v})$ foetal calf serum, $1 \%$ MEM non-essential amino acids solution (M7145, Sigma-Aldrich), $1 \%$ antibiotics/antimycotics, $1 \%$ L-glutamine (25030081, Gibco), $0.025 \mathrm{~g} / \mathrm{ml}$ of ascorbic acid (A92902, Sigma-Aldrich), 10 ng/mL TGF- $\beta-1$ (T7039, Scientific laboratories supplies Ltd) and 5ng/mL FGF-2 (SRP4037, Sigma-Aldrich). Triplicates of samples were printed for each time point for the biochemical, histological and mechanical studies. Samples were cultured in dynamic conditions using an orbital shaker and medium was changed twice a week.

\subsection{Biochemical assays}

Samples were digested overnight in papain solution (L-cysteine $0.042 \mathrm{mg} / \mathrm{ml}$, PBS, papain $25 \mu \mathrm{g} / \mathrm{ml}$, EDTA $0.005 \mathrm{M}$ ) at $60^{\circ} \mathrm{C}$. Total DNA was quantified on the papain digests using a Picogreen DNA assay (Invitrogen) according to the manufacturer's instructions. Total Glycosaminoglycans (GAGs) content was determined by photo spectrometry at $520 \mathrm{~nm}$ after the reaction with dimethylmethylene blue using a microplate reader (Tecan). GAG content was quantified using chondroitin sulphate 
(Sigma-Aldrich) as a standard. Calculated concentrations in each digested sample were expressed as GAGs/DNA. All the studies were performed in triplicates.

\subsection{Histological analysis}

Samples were fixed in 7\% paraformaldehyde, washed three times with PBS and immersed in 15\% sucrose for 24 hours and $30 \%$ sucrose for 12 hours. Afterwards, the samples were embedded in OCT and snap frozen using liquid nitrogen. Samples were cryo sectioned into $10 \mu \mathrm{m}$ slices and stained with fast green (F7552, Sigma-Aldrich) and Safranin-O (HT90432, Sigma-Aldrich) dyes to identify the presence of GAGs. The stained sections were examined using a light microscope (Leica DM IRB).

Cryo sectioned samples were also stained with immunohistochemistry for detection of collagen II. All sections were permeabilised using $0.1 \%$ Triton $X$ in PBS and blocked with $3 \%$ donkey serum albumin (D9663, Sigma-Aldrich). Next, sections were incubated with the primary antibodies for collagen type II (ab34712 rabbit anti-collagen type II antibody, ab34712, Abcam) at $4{ }^{\circ} \mathrm{C}$ overnight. Subsequently, sections were incubated with the secondary antibody Alexa Fluor 488 (ab150073 Donkey anti-rabbit IgG, Abcam) at room temperature for two hours. Finally, sections were co-stained with Hoechst $332581 \mu / \mathrm{ml}$ (Sigma-Aldrich) for 15 minutes. Samples were imaged under the fluorescent microscope (Leica DM IRB).

\subsection{Mechanical testing}

Compression testing was conducted on the samples using TA HD plus texture analyser (Stable micro systems). Each specimen was compressed at a displacement rate of $1 \mathrm{~mm} / \mathrm{min}$ to a maximum force of $5 \mathrm{~kg}$. All tests were performed in triplicates. Young's modulus (MPa) was calculated from the stress-strain curve as the slope of the initial linear portion of the curve (5\%-10\%), with any toe region due to the initial settling of the specimen neglected.

\subsection{D co-printing and culture of PCL/GelMA/chondrocytes constructs}

GeIMA/chondrocytes solution was prepared the same way than mentioned previously. Structures were designed using newly-developed software integrated into an Excel spreadsheet ('Scaffold Designer' supplied as supplementary information). Scaffolds were designed with the overall dimensions $2 \mathrm{~cm} \times 2 \mathrm{~cm} \times 2 \mathrm{~mm}$. PCL pellets ( $\mathrm{Mn}=40000-50000 \mathrm{~g} \mathrm{~mol}-1$ Sigma-Aldrich, UK) were extruded at a temperature of $77^{\circ} \mathrm{C}$ at a rate of $16 \mathrm{~mm} / \mathrm{s}$ PCL strands were printed $2 \mathrm{~mm}$ apart and GelMA was printed in the central part in between the two PCL strands. One layer of GelMA was printed every two repeated layers of PCL. The number of repeated layers refers to the number of 
consecutive layers with the same printing path (Figure 7A). A total of 8 layers of PCL and 4 layers of GelMA were printed. GelMA was cross linked for 20 seconds after deposition.

\subsection{Statistical analysis}

Statistical analysis was performed using Prism version 8.0 (GraphPad Software, USA). Statistical significance was determined by two-way ANOVA followed by uncorrected Fisher's least square difference multiple-comparison post hoc test. Plots are means with error bars indicating the standard error. Statistically significant values are presented as ${ }^{*} p<0.05,{ }^{* *} p<0.01,{ }^{* * *} p<0.001$ and ${ }^{* * *} p<$ 0.0001 .

\section{Results and Discussion}

\subsection{GelMA rheological properties}

The rheological properties of hydrogels are one of the most important parameters which determine their printability [21]. Printability for a bioink can be determined by the ease with which it could be printed with good resolution and maintenance of its structure after printing [22]. Previously, a viscosity range of 1 to $10 \mathrm{~Pa} \cdot \mathrm{s}$ (at shear rate of 100 1/s) for hydrogels has been demonstrated to be suitable for 3D extrusion-based bioprinting [23]. In order to identify a suitable concentration and temperature for bioprinting GelMA, a rheological study was performed. Viscosities of $10 \%, 15 \%$ and $20 \%$ GelMA were measured as a function of temperature. As shown in Figure 1A, it was observed that the viscosity of GeIMA is temperature and concentration dependant. To achieve viscosities within the range of 1 - $10 \mathrm{~Pa}$-s different temperatures were required for the three different GelMA concentrations. As temperatures lower than $15^{\circ} \mathrm{C}$ could be detrimental for the cells viability [24], a printability temperature window was set from $15^{\circ} \mathrm{C}$ to $37^{\circ} \mathrm{C}$. As observed in Figure 1 only $15 \%$ and $20 \%$ GelMA hydrogels fit into this printability window. Based on the rheological results, $15^{\circ} \mathrm{C}$ and $20^{\circ} \mathrm{C}$ were selected as the printing temperatures for $15 \%$ and $20 \%$ GelMA respectively. The viscosities at these temperatures are comparable to the viscosity of $10 \%$ printable GeIMA supplemented with gellan gum [25].

Due to the photo crosslinkable property of GeIMA, once the strand is printed it can be immediately UV crosslinked. The immediate crosslinking allows the strand to preserve its structure and support itself without the need of temperature control. The minimal UV dosage necessary to crosslink GeIMA and increase its complex modulus was investigated in this section. Different concentrations of GelMA were exposed to UV for 10, 20 and 30 seconds and the complex modulus was measured using a rheometer. Figure 1B shows the increase in the complex modulus with the increase of UV exposure. After 10 seconds of exposure, an average of 10-fold increase was observed for all concentrations compared with the non-exposed samples. A 10.5, 30.5 and 59.5-fold increase was observed after 
20 seconds and a 40, 58 and 85-fold increase after 30 seconds for 10\%, 15\% and 20\% GelMA respectively. Twenty seconds was chosen as the crosslinking time because is the minimum crosslinking time where a difference in modulus can be observed between the three concentrations.

A

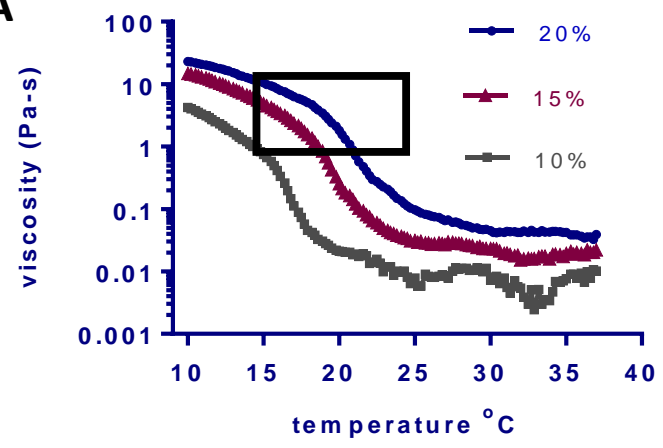

B

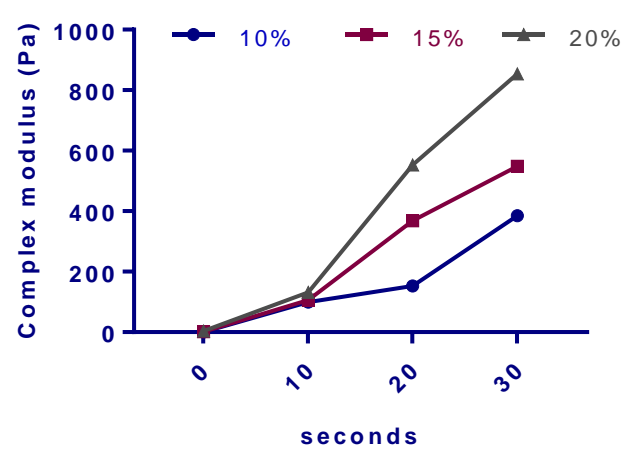

Figure 1. Rheological properties of GelMA hydrogels of different concentrations. A) Viscosity of three different concentrations of GeIMA (10\%, 15\% and $20 \%$ ) as a function of temperature. The viscosities were measured at a shear rate of $100 \mathrm{~s}^{-1}$. Black rectangular box represents the viscosity range of 1-10 Pa.s. B) Complex moduli of $10 \%, 15 \%$ and $20 \%$ GelMA after UV exposure for 0,10 , 20 and 30 seconds at an UV intensity of $31 \mathrm{~mW} / \mathrm{cm}^{2}$.

\subsection{Effects of the 3D printing process on chondrocytes viability and genotoxicity}

Different variables can affect cell viability during extrusion-based bioprinting processes [22]. The ones considered in this study were the concentration of GeIMA, needle gauge, printing temperature, printing time and the UV exposure for crosslinking. All these parameters were studied individually in order to determine their effects on cell viability.

During the printing process the cells have to remain encapsulated in non-crosslinked GelMA for a period of up to 2 hours. As part of the viability assessment the first step was to study if the noncrosslinked material has any cytotoxic effect on the cells. For this reason, the effect of different concentrations of GelMA (10\%, $20 \%, 30 \%)$ on cell viability was assessed by encapsulating the cells within the material for 2 hours at room temperature. The results in Figure 2A show just a 3\% reduction in viability of the chondrocytes when cultured in GelMA compared with the monolayer control. Additionally, it was observed that there was no significant effect on cells viability among the tested concentrations, with all of them showing an average of $90 \%$ viable cells.

Other parameters that may influence cell viability include the printing temperature $\left(15^{\circ} \mathrm{C}\right.$ and $20^{\circ} \mathrm{C}$ for $15 \%$ and $20 \%$ GelMA) and the time exposed to it. Cells encapsulated in GelMA have to remain in a cooled syringe during printing and this time could vary from minutes to approximately 2 hours depending on the size of the structure and the number of replicates. Three different temperatures 
$15^{\circ} \mathrm{C}, 20^{\circ} \mathrm{C}$ and $37^{\circ} \mathrm{C}$ were tested for their effect on cell viability with time frames from 15 minutes to 2 hours. Figure 2B shows that the three different temperatures did not have a significant effect on cells viability for the various printing time periods suggesting that the cells can remain viable if these temperatures are used in order to increase GelMA viscosity.

Another parameter we assessed was the needle gauge. The shear stress that the cells experience during printing depends on the internal diameter of the needle, dispensing pressure and bioink consistency [22]. Some studies have shown that high shear stress can cause cell death [26]. For our studies, gauges 27 (203 $\mu \mathrm{m}$ internal diameter (ID)) and 30 (180 $\mu \mathrm{m}$ ID) were chosen because high printing resolution (small strand diameter) was desirable. The dispensing pressure was kept constant at the lowest ( 2 bar) that allowed the extrusion of the material. The viability was quantified on day 0 immediately after printing and on day 3 . An average of $80 \%$ viable cells was obtained with both needle gauges (Figure $\mathbf{2 C}$ ), which is an acceptable viability and is comparable to previous publications [27,28]. Liu and co-workers showed that viabilities of HUVECS encapsulated in GelMA and printed with a G27 needle were $85.1 \% \pm 7.0 \%$ at day 1 and $89.3 \% \pm 0.6 \%$ at day 7 [28]. Similarly, Billiet and co-workers showed an average viability of $90 \%$ for HepG2 cells encapsulated in GelMA and printed with the same needle [27]. Even though both of our needle diameters showed similar viability, for the following studies G27 was chosen because G30 required increased dispensing pressure for the formation of a uniform strand and nozzle blocking occurred more frequently (data not shown).

As a UV-activatable photoinitiator (Irgacure 2959) was used for crosslinking GelMA, we investigated the effect of UV exposure on cell viability and genotoxicity. The UV cytotoxicity and genotoxicity can vary depending on the UV dosage which is determined by the UV intensity and the time during which the cells are exposed (UV dosage $=$ Intensity $\mathrm{mW} / \mathrm{cm}^{2} \times$ time (s)) [29]. It was found that 20 seconds at an intensity of $31 \mathrm{~mW} / \mathrm{cm}^{2}$ (UV dosage $0.62 \mathrm{~J} / \mathrm{cm}^{2}$ ) was the minimal dosage needed to crosslink GeIMA. We then investigated what was the maximum dose that the cells could tolerate. During the printing process cells will be receiving incremental exposure as each subsequent layer requires UV crosslinking and the penetration of UV. To study the effect of the UV dosage on the viability and genotoxicity, chondrocytes were exposed to UV from 10 seconds to 12 minutes (UV dosages from 0.31 to $22 \mathrm{~J} / \mathrm{cm}^{2}$ ). Figure 2D shows that there is no significant effect on cells viability when UV exposure time varied from 10 seconds to 3 minutes, which agrees with previous work [30],[31],[32]. In contrast only $20 \%$ of the cells remained viable after 6 minutes (UV dose $11.16 \mathrm{~J} / \mathrm{cm}^{2}$ ) and $0 \%$ after 12 minutes (UV dose $22.32 \mathrm{~J} / \mathrm{cm}^{2}$ ). These results were comparable to similar studies that showed decreased viability of primary chondrocytes after exposed to UV dosages higher than 5 $\mathrm{J} / \mathrm{cm}^{2}[33][34]$. 
A

GeIM A concentrations

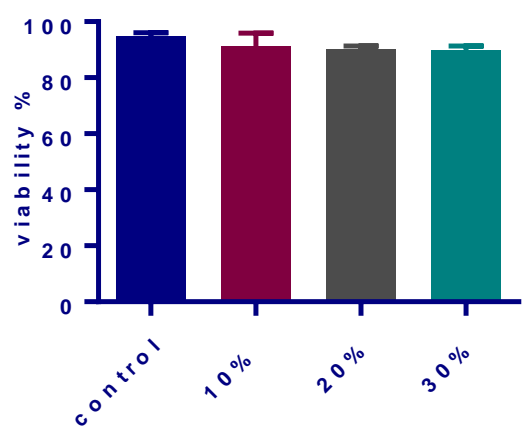

C

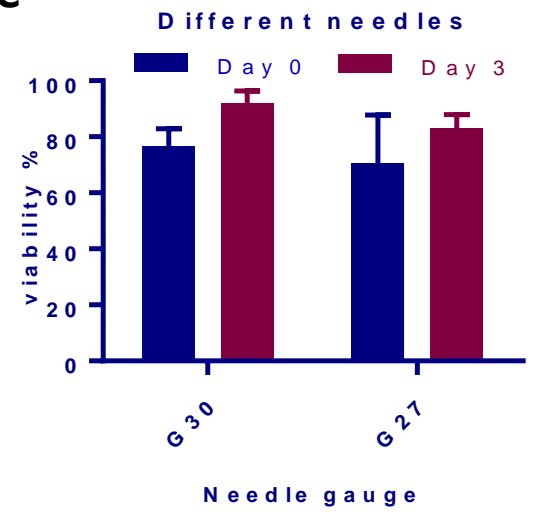

B Tem perature
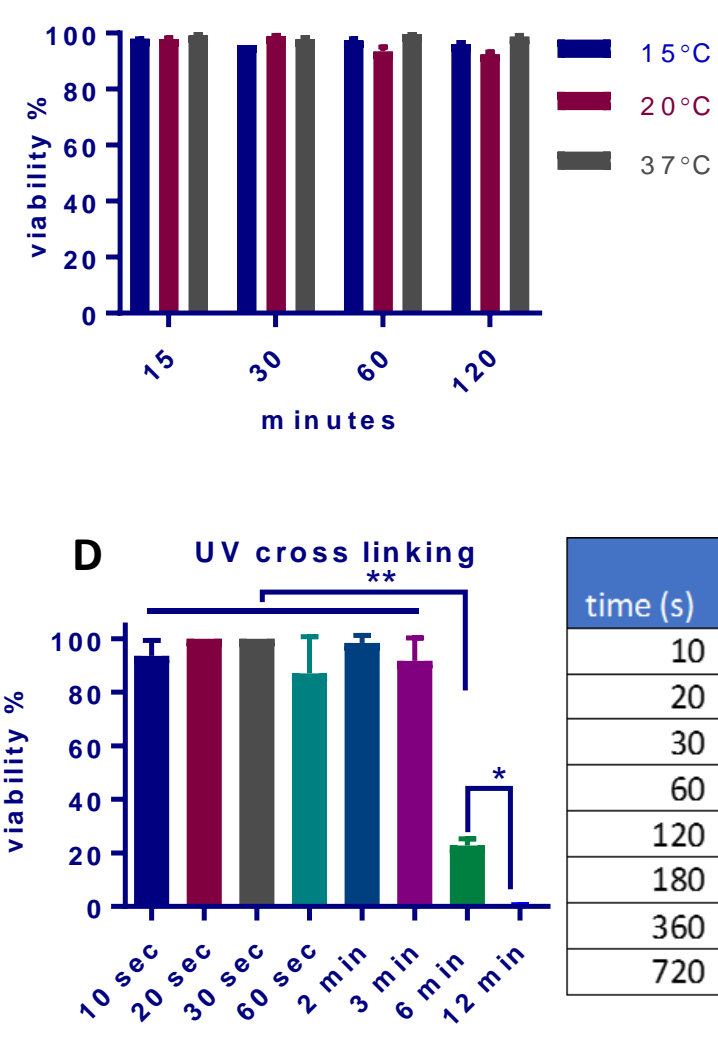

\begin{tabular}{|r|r|}
\hline time $(\mathrm{s})$ & \multicolumn{2}{|l|}{$\begin{array}{l}\text { UV dosage } \\
\left(\mathrm{J} / \mathrm{cm}^{2}\right)\end{array}$} \\
\hline 10 & 0.31 \\
\hline 20 & 0.62 \\
\hline 30 & 0.93 \\
\hline 60 & 1.86 \\
\hline 120 & 3.72 \\
\hline 180 & 5.58 \\
\hline 360 & 11.16 \\
\hline 720 & 22.32 \\
\hline
\end{tabular}

exposure time

Figure 2. Chondrocytes viability assessment with LIVE/DEAD under different 3D printing parameters and UV dosages. The control group were chondrocytes cultured in monolayer on tissue culture plastic. A) Viability of chondrocytes encapsulated in a range of different concentrations of GelMA for $24 \mathrm{~h}$ (casted samples). B) Viability of cells encapsulated in $20 \%$ GelMA exposed at $15^{\circ} \mathrm{C}, 20^{\circ} \mathrm{C}$ and $37^{\circ} \mathrm{C}$ for a period of 15 minutes to 2 hours. C) Viability of chondrocytes encapsulated in $20 \%$ GelMA after been extruded through two different needle gauges G30 (180 $\mu \mathrm{m}$ internal diameter) and G27 $\left(210 \mu \mathrm{m}\right.$ internal diameter) at $18^{\circ} \mathrm{C}$. No statistical difference was observed between both groups. D) Viability of chondrocytes after different UV exposition times (UV intensity $=31 \mathrm{~mW} / \mathrm{cm}^{2}$ ). Table shows the relevant UV dosages. ${ }^{*} p<0.05,{ }^{* *} p<0.01$. The data expressed is the mean number $(\mathrm{n}=5)$. Error bars represent the standard error.

Studies have shown that UV light causes cell death by damaging the DNA which can affect transcription, replication or induce apoptosis [35]. Therefore, even though cells remained viable after UV exposure for up to $5.58 \mathrm{~J} / \mathrm{cm}^{2}$, it is important to consider the genotoxicity that could induce further cell death or changes in genomic stability. This effect was assessed by measuring the expression of $\mathrm{Y}-\mathrm{H} 2 \alpha \mathrm{X}$, an early detection marker of DNA damage [36]. Cells were exposed to UV from 10 seconds to 10 minutes (UV dosages in Figure 3B) and $\mathrm{y}-\mathrm{H} 2 \mathrm{AX}$ expression was analysed 24 hours after the exposure. Quantification was performed by normalising the number of cells expressing $\mathrm{Y}-\mathrm{H} 2 \mathrm{AX}$ to 
the total cell number. Figure 3A shows the cells expressing $\mathrm{y}-\mathrm{H} 2 \mathrm{AX}$ in green and the cell nuclei stained with DAPI (blue). Cells exposed to 10 seconds and 1 minute (UV dosage 0.31 and 1.86 $\mathrm{J} / \mathrm{cm}^{2}$ ) did not expressed any detectable DNA damage while $50 \%$ of the cells exposed for 2.5 minutes (UV dosage $4.65 \mathrm{~J} / \mathrm{cm}^{2}$ ) were DNA damaged. The damaged cell population increased to $90 \%$ after exposure for 10 minutes (UV dosage $18.6 \mathrm{~J} / \mathrm{cm}^{2}$ ) (Figure 3B).

Based on these characterisations, the appropriate printing parameters and UV crosslinking conditions were selected for subsequent bioprinting experiments. GelMA concentration of $15 \%$ and $20 \%$ was selected because they fit in the printability window when printed at $15{ }^{\circ} \mathrm{C}$ and $20{ }^{\circ} \mathrm{C}$ respectively. The needle gauge $27(203 \mu \mathrm{m})$ was chosen because a lower dispensing pressure can be used compared to gauge 30. For this study a maximum of four GelMA layers were printed in order to not exceed the limit of genotoxic UV dosage.
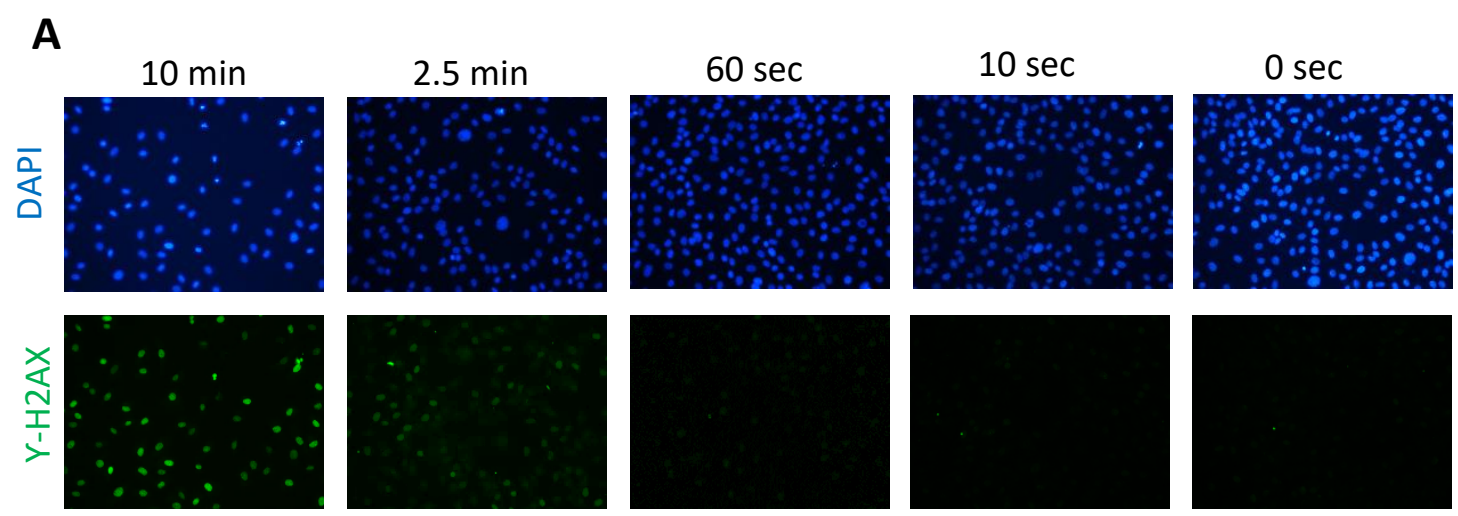

\section{B}
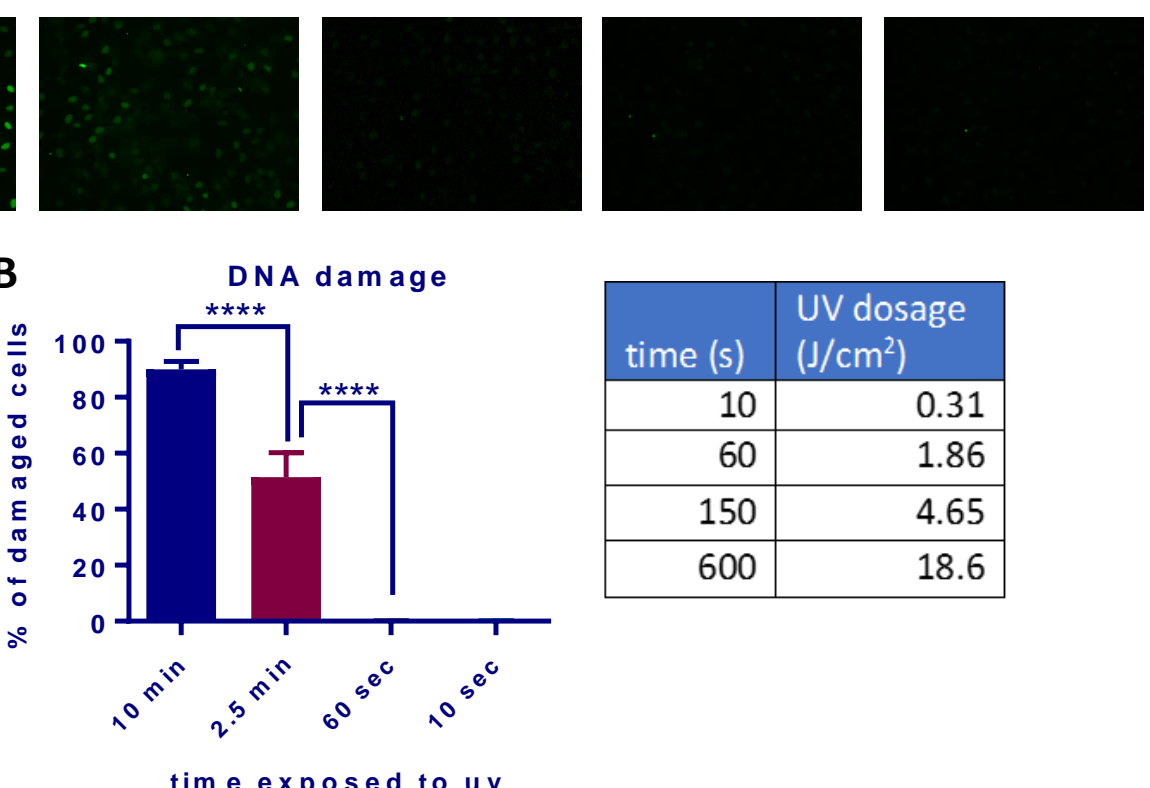

\begin{tabular}{|r|r|}
\hline time $(\mathrm{s})$ & $\begin{array}{l}\text { UV dosage } \\
\left(\mathrm{J} / \mathrm{cm}^{2}\right)\end{array}$ \\
\hline 10 & 0.31 \\
\hline 60 & 1.86 \\
\hline 150 & 4.65 \\
\hline 600 & 18.6 \\
\hline
\end{tabular}

Figure 3. Evaluation of genotoxicity on chondrocytes caused by UV exposure. This study was performed in cell monolayers in tissue culture plastic. A) Representative images of the chondrocytes stained for $\mathrm{Y}-\mathrm{H} 2 \mathrm{AX}$ expression. The top row shows cells stained with DAPI representing the total number of cells and the bottom shows cells stained for $Y-H 2 A X$ representing DNA double strand damage. B) Quantification of the genotoxicity by UV exposure (31 $\mathrm{mW} / \mathrm{cm}^{2}$ Intensity) on chondrocytes evaluated by the percentage of cells that expressed $\mathrm{Y}-\mathrm{H} 2 \mathrm{AX}$. The table converts UV exposure time to dosage. ${ }^{* * *} p<0.0001$. The data expressed is the mean number $(n=5)$. Error bars represent the standard error. 


\subsection{In vitro culture of 3D printed chondrocyte-laden GelMA constructs}

The proliferation and ability to produce cartilage ECM of chondrocytes following 3D bioprinting was examined in two GelMA concentrations (15\% and 20\%) for up to 50 days. During cultivation, cell proliferation and mechanical properties of the cell-laden constructs were quantified at day $0,14,21$ and 50. Gross morphology of the samples, cells distribution, secretion of GAGs and collagen II were assessed at the end of the culture period.

Figure 4A shows representative bright field (top row) and fluorescent images (bottom row) of the printed samples on day 0 and day 50 in vitro. In the bottom row the cells were stained with calcein in order to observe their distribution within the scaffolds on day 0 and 50. Firstly, it was observed that day 0 samples printed with $20 \%$ GelMA showed more uniform strands and pores compared to $15 \%$ GelMA due to higher viscosity (Figure 4A). Secondly, the 3D bioprinted GelMA/chondrocytes samples were porous and translucent on day 0 of culture, and became opaque with closed pores by day 50 (Figure 4A). This change in gross morphology of the structures was due to the cell expansion into the pores and the secretion of ECM. It has been found from the images of cryo-sectioned chondrocyte-laden GelMA that cells expanded to the pores (Figure 4B). GeIMA is represented in red in Figure 4B. It was also observed that a higher number of cells were located at the periphery of the sample and inside the pores; cells were still present within the GelMA strands but with a lower number (Figure 4B). These results suggest that the chondrocytes that migrated to the pores proliferated faster in these locations, possibly because they had easier access to nutrients and oxygen. This difference in proliferation rate within different parts of a scaffold due to nutrients diffusion has been reported previously [37]. Additionally, these results highlight the importance of incorporating pores within the hydrogel structures to allow enough nutrients and oxygen to reach the cells. 
Day 0

A
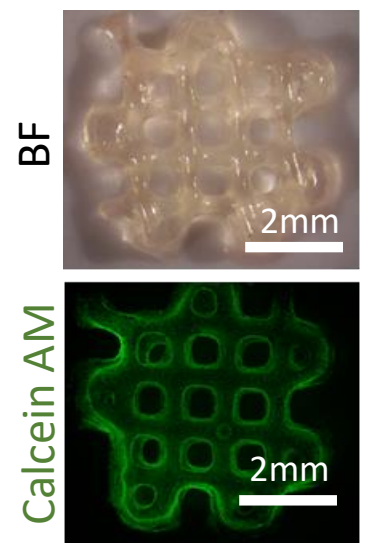

B

\section{DAPI/GelMA day 50}

Day 50

$15 \%$
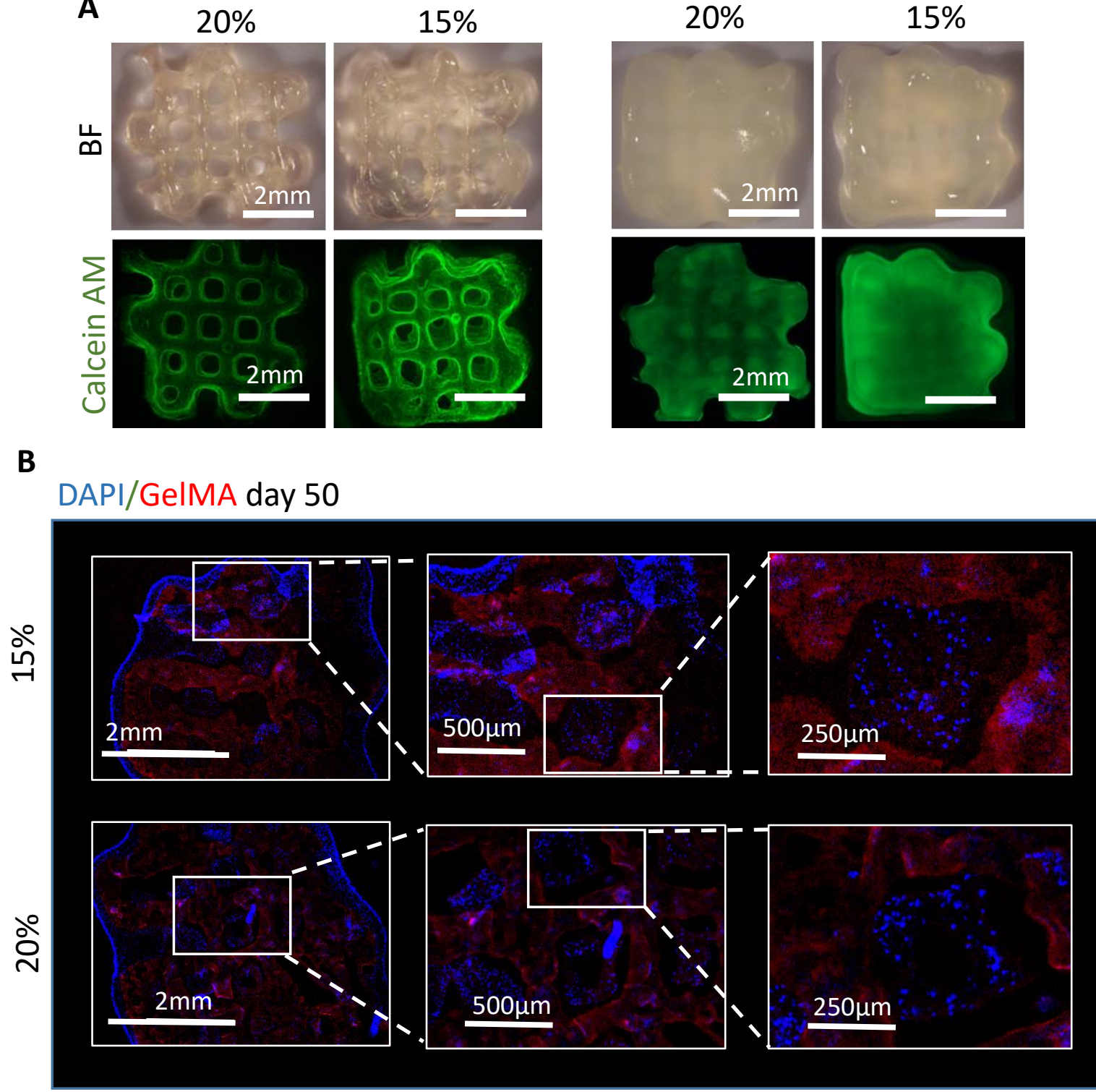

Figure 4. Gross morphologies of 3D bioprinted four-layer constructs with GelMA/chondrocytes. A) Top row: bright field images of 3D bioprinted samples at day 0 and day 50 after cultivation; Bottom row: fluorescence images of cells stained with calcein AM on day 0 and day 50 showing the overall cell distribution. Scale bars represent $2 \mathrm{~mm}$. B) Cryo sections of GelMA/chondrocytes constructs stained with DAPI (blue) representing cell distribution at day 50. GelMA distribution is represented in red (auto florescence). Areas in white boxes are magnified in images on the right.

Proliferation of the cells was quantified at different time points of the culture period based on DNA content. Cell proliferation in both GelMA concentrations doubled from day 0 to day 14 (Figure 5A). 
After day 14 no proliferation was detected in either of the gels. This was expected because primary chondrocytes tend to stop proliferating and senesce after serval weeks of in vitro culture [38].

Evaluation of the ECM synthesised by the chondrocytes was done by quantifying the amount of secreted GAGs, histological staining of GAGs and staining of collagen type II using Immunohistochemistry. The amount of GAGs in the samples increased 6 fold from day 0 to 21 of culture with no statistically significant difference in the secreted amount between the gels with two different concentrations. However, there was no increase of GAGs from day 21 to 50 which could be due the high increase in cell density after 21 days (Figure 5B). This effect has been previously observed in 3D culture of chondrocytes in alginate beads [39]. Kobayashi et al observed that beads with a cell concentration from 1 to $10 \times 10^{6} \mathrm{cells} / \mathrm{ml}$ showed increase in GAGs secretion during culture, but at higher concentrations the secretion was limited. We had an initial concentration of 10 x $10^{6} \mathrm{cells} / \mathrm{ml}$ and it doubled by day 14 , which could have affected the rate of GAGs secretion from day 14 onwards. Another possible explanation to the cease in GAGs secretion is cartilage tissue maturation. It has been previously reported that collagen concentration and pyridinoline cross-link concentration increased with maturation, whilst the glycosaminoglycan concentration and percentage water content remain unchanged or decrease slightly [40]. This could explain the increase in mechanical properties of the samples at day 50 ( Figure 5D). The presence of GAGs at day 50 was also confirmed qualitatively by histological staining with Safranin O (Figure $\mathbf{5 C}$ ). Additionally, the presence of collagen II in the GelMA was confirmed using immunohistochemistry at day 50 (Figure 5C bottom row).

The mechanical properties of the engineered tissue are an important factor to consider because the tissue has to possess sufficient strength and elasticity to withstand surgical manipulation as well as mechanical stresses in situ after implantation to avoid collapse of the reconstructed nose [41]. The Young's moduli of the samples were measured on four different time points by compression testing. The young's modulus of $20 \%$ GeIMA was approximately twice the value of the $15 \%$ GelMA at day 0 . The moduli of both cell-laden gels increased from day 0 to day 21 , and ratio of modulus between the $20 \%$ and the $10 \%$ gel decreased slightly. At day 50 the Young's modulus of $20 \%$ and $15 \%$ were 4 and 6 times higher, respectively, compared to day 0 (Figure 5D). This increase at day 50 was possibly caused by the maturation of the tissue and increase in collagen content [40]. The modulus of $20 \%$ cell-laden gels at day $50(0.8 \mathrm{MPa})$ was similar to that of lateral nasal cartilage $(0.98 \mathrm{MPa})$ but lower than septal cartilage (2.72 MPa) [42]. Due to insufficient mechanical properties of the cellladen gels, it is important to add a reinforcement material within the $3 \mathrm{D}$ printed structures to increase the overall structural mechanical properties. 
A

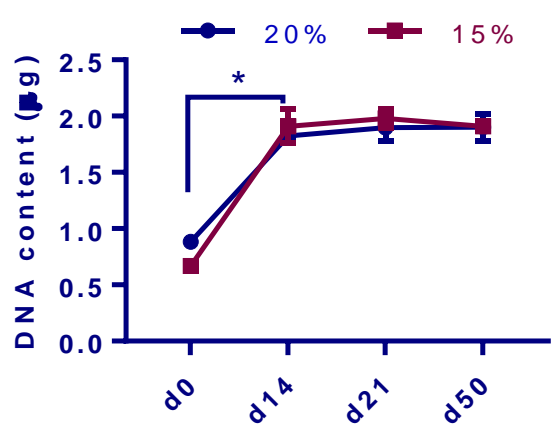

C

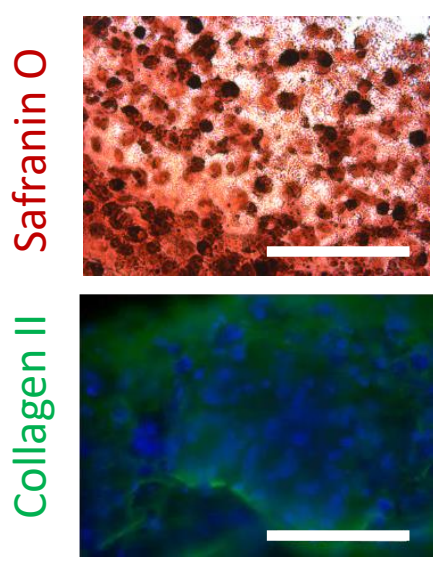

B

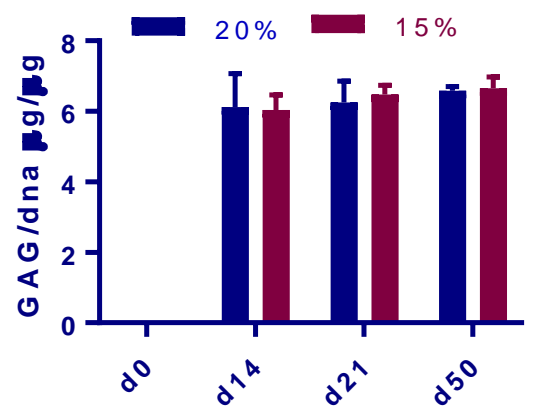

D

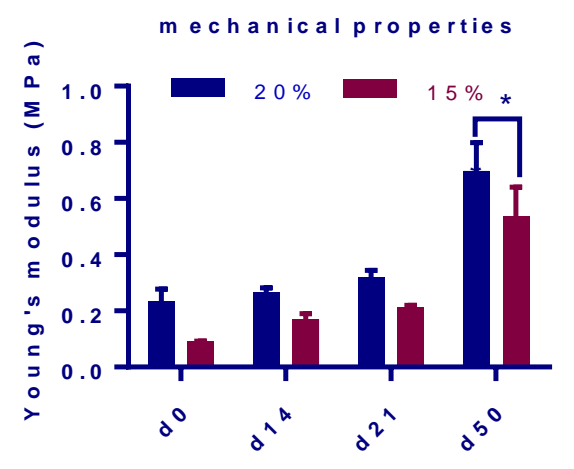

Figure 5. Proliferation, GAGs secretion and mechanical properties of 3D bioprinted constructs with GeIMA/chondrocytes during culture. a) Proliferation of chondrocytes quantified by DNA content on day 0, 14, 21 and 50. b) GAGs content on day 0, 21 and 50. C) Histological staining of GAGs (Safranin O) and collagen II on day 50. GAGs appear orange-red and the cell nuclei appear darker red. Cell nuclei were stained by DAPI in blue. Scale bars represent $100 \mu \mathrm{m}$. D) Mechanical properties measured with compression test of samples at different time points. Young's modulus (MPa) was calculated from the stress-strain curve as the slope of the initial linear portion of the curve $(5 \%$ $10 \%)$. ${ }^{*} p<0.05$. The data expressed in the mean number $(n=3)$. Error bars represent the standard error.

\subsection{Multi-material bioprinting and culture of PCL/GeIMA/chondrocytes porous constructs}

Polycaprolactone was used as a reinforcement material to create $3 D$ constructs with improved mechanical stability. PCL is a FDA approved thermoplastic polymer that has been widely used in 3D printing and also has been previously used for structural purposes to print complex structures [12]. PCL scaffolds alone with the same porosity have a Young's modulus of $28.5 \mathrm{Mpa}$ [15]. GelMA 20\% was used as a cell carrier rather than $15 \%$ because of better printing fidelity and there was no difference on cell proliferation or ECM secretion between them. Chondrocytes-laden GeIMA were printed between the PCL strands. Pores were incorporated in the design of the constructs to facilitate 
diffusion of nutrients and oxygen. The multi-material samples had dimensions of $20 \times 20 \times 2 \mathrm{~mm}^{3}$ (Figure 6A). The pores size ranged from 500 to $650 \mu \mathrm{m}$ (Figure 6C and D). The chondrocytes were stained with calcein AM to show their distribution in the final structures (Figure 6D). A compression test was performed on GelMA alone and GeIMA/PCL samples to identify the difference in mechanical properties. Figure 6E shows that the Young's modulus of the GeIMA/PCL samples was 37 times higher than that of GeIMA. It is worth noting that the Young's modulus of GeIMA/PCL samples was similar to PCL alone samples with the same porosity [15].
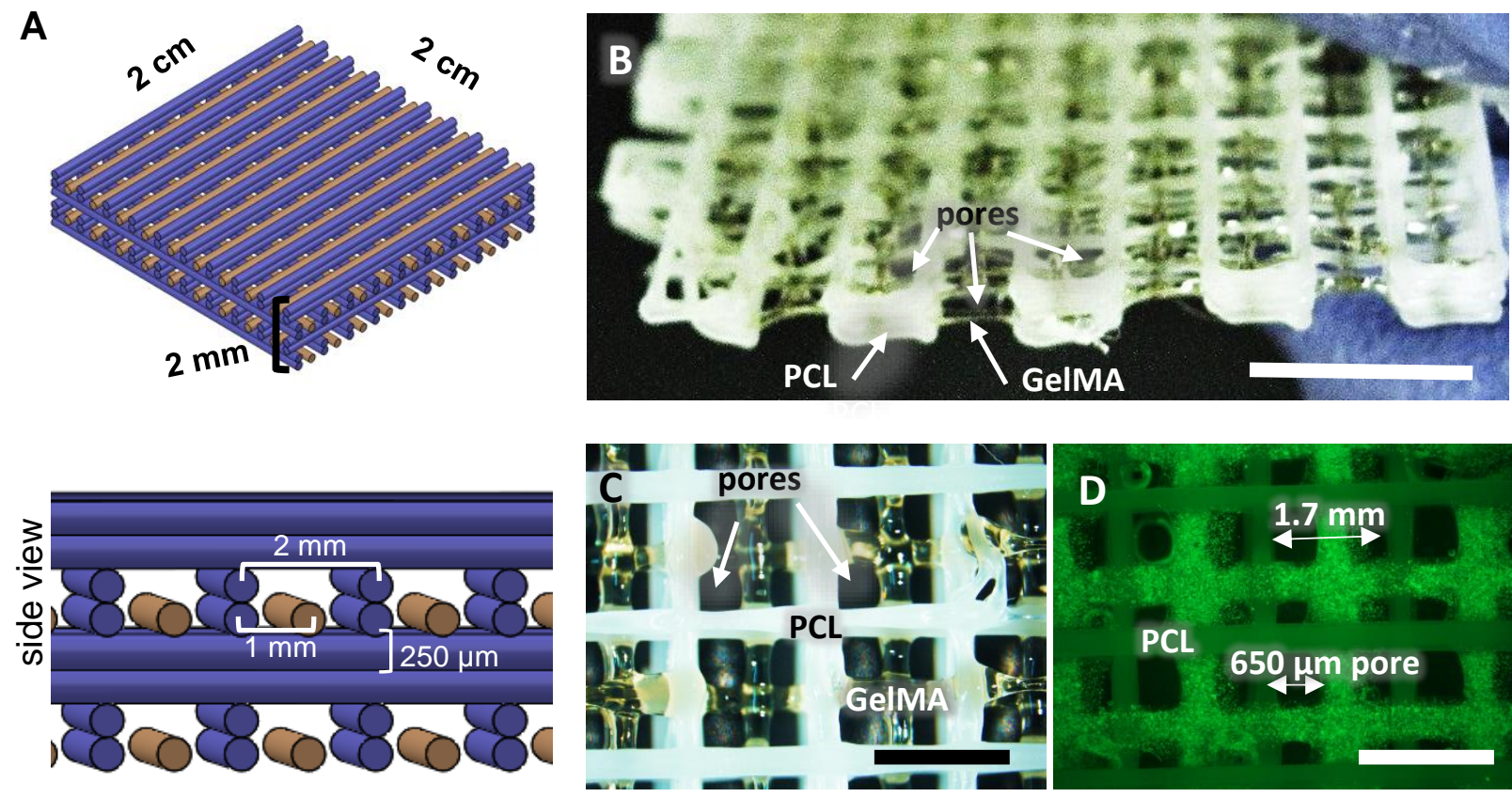

$\mathbf{E}$

\begin{tabular}{|l|l|}
\hline Material & Young's modulus (MPa) \\
\hline GelMA & $0.75 \pm 0.05$ \\
\hline GeIMA/PCL & $28 \pm 3$ \\
\hline
\end{tabular}

Figure 6. Multi-material bioprinting of porous constructs with PCL and GelMA/chondrocytes. A) Schematic of the printed structure with PCL (blue) and GelMA (orange). B) A representative image of a printed porous construct with 8 layers of PCL and 4 layers of GelMA on the $Z$ direction. Sample dimensions are $20 \times 20 \times 2 \mathrm{~mm}^{3}$. Scale bar represents $5 \mathrm{~mm}$. C) Bright field image of the construct showing the PCL, GeIMA and pores distribution from a top view. Scale bar represents $2 \mathrm{~mm}$. D) A fluorescence image indicating chondrocytes (stained with calcein AM) encapsulated in GelMA, pores and PCL strands. Scale bar represents $2 \mathrm{~mm}$. E) Young's modulus of GelMA and GeIMA/PCL constructs at day 0 . 
To study the regeneration of neocartilage tissue in vitro, the samples were cultured for a period of 21 days and analysed at different time points. A change in GelMA colour was notable, going from transparent to white. In addition, the strands gradually spread into the pore space and the width of the strands increased from approximately $300 \mu \mathrm{m}$ to $600 \mu \mathrm{m}$ after 21 days (Figure 7A), which suggested cell proliferation and ECM secretion. Swelling could be another explanation for the increase in strand diameter. But previous studies have shown that GelMA 20\% has a swelling ratio of $10 \%$ [43], which means in our case the GelMA strand diameter would be $330 \mu \mathrm{m}$ rather than 600 $\mu \mathrm{m}$. The fluorescence images (Figure 7A) also show that cell-laden GelMA strands filled part of the pores by day 21. Proliferation of the cells was confirmed by measuring DNA content (Figure 7B) which showed a gradual increase. Cell proliferation seemed to reach a plateau by day 14 of culture, similar to what was observed in pure cell-laden GeIMA structures. These observations emphasise the importance of taking into account the size of the pores during the design of the scaffold to allow enough space for cell expansion. Secretion of cartilage related matrix was confirmed by measuring the content of GAGs, showing a rapid increase from day 0 to day 7 followed by a more gradual increase afterwards (Figure 7C). Collagen II and GAGs were also present confirmed by immunoand histological staining of the cell-laden hydrogel strands (Figure 7D). These results suggest the formation of neocartilage in the multi-material cellular scaffolds, similar to the results achieved by Kang et al in their in vitro study [11]. However, in order to achieve a full comparison with their multimaterial bioprinted constructs, in vivo studies will need to be carried out in the future on our cellular scaffolds. 
A

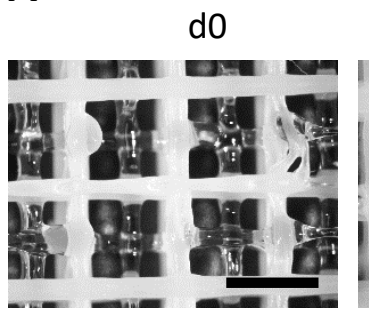

d14

$\mathrm{d} 21$
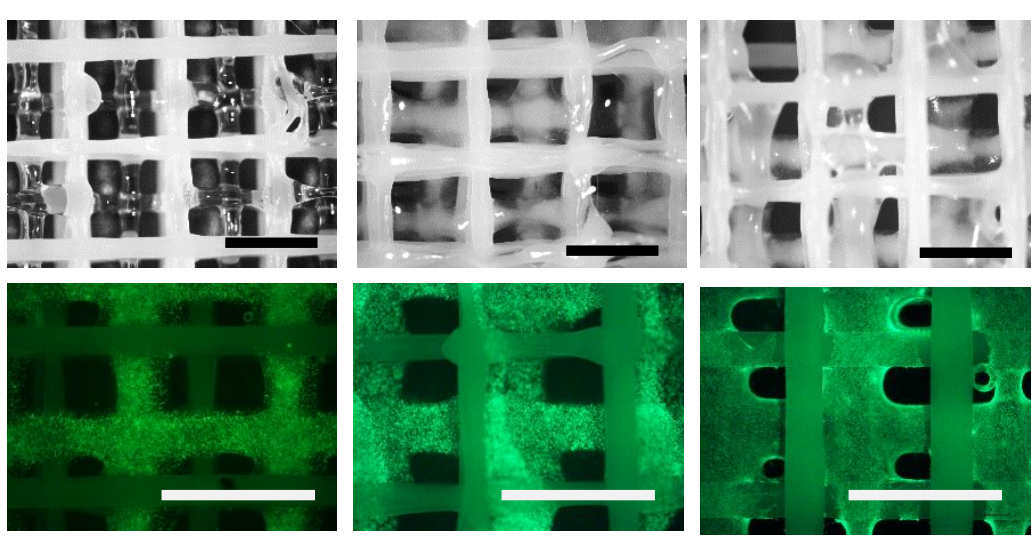

B

proliferation

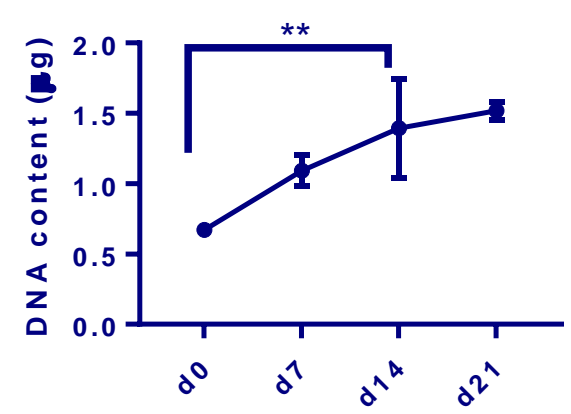

C

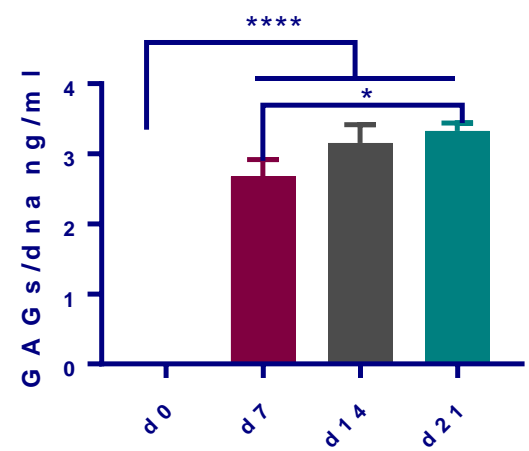

D

\section{Collagen II/DAPI}
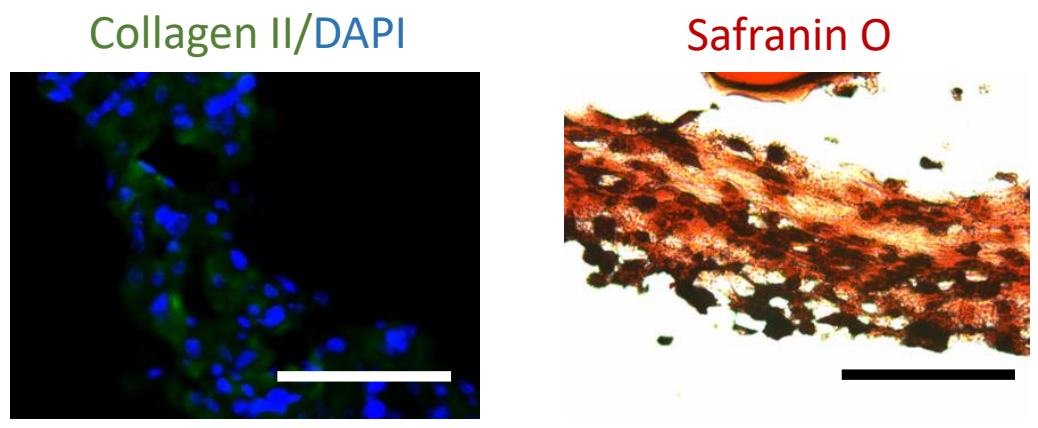

Figure 7. Bioprinted PCL/GelMA/chondrocytes constructs in culture for 21 days. A) top row: representative bright field images of gross change in colour and shape of the samples during a 21day culture period. Scale bars represent $1 \mathrm{~mm}$. Bottom row: representative fluorescence images of chondrocytes (green) distribution. Scale bars represent $2 \mathrm{~mm}$. B) Chondrocytes proliferation measured by DNA content during 21 days. C) GAGs content during 21 days in culture. D) Histological sections of samples on day 21. Left: Immunostaining for collagen II in green and DAPI in blue. Right: Safranin O staining of GAGs. Scale bars represent $200 \mu \mathrm{m}$. ${ }^{*} p<0.05^{* *} p<0.01$. Data is expressed in the mean number $(n=3)$. Error bars represent the standard error.

In this study 3D printed cell-laden GelMA/PCL porous composite constructs were fabricated by controlling the viscosity of GeIMA with temperature. GeIMA has been previously used for cartilage 
tissue engineering and 3D bioprinting, which demonstrated that this material supports chondrocytes proliferation, phenotype and ECM secretion[44],[45],[19]. However, a detailed study of the effects of the GelMA printing process on cell viability has not been performed. In this work we individually evaluated each of the parameters of the 3D printing process with GelMA and their effects on chondrocyte viability. We found that the GelMA concentrations from $10 \%$ to $30 \%$ and temperatures ranging from $15^{\circ} \mathrm{C}$ to $37^{\circ} \mathrm{C}$ did not affect cell viability during printing. In contrast, extruding the cells through the nozzle reduced the viability by approximately $20 \%$, and prolonged UV exposure drastically reduced the viability by $80 \%$ after $11.16 \mathrm{~J} / \mathrm{cm}^{2} \mathrm{UV}$ dosage. It was also found that even though viability of the cells was not affected after $5.58 \mathrm{~J} / \mathrm{cm}^{2} \mathrm{UV}$ dosage, $50 \%$ of the cells had DNA damage after $4.65 \mathrm{~J} / \mathrm{cm}^{2}$ UV dosage, which could lead to mutagenesis of the cells.

Once that we found the appropriate parameters for printing with GeIMA without having detrimental effect on the cells, we employed a multi-material approach for the fabrication of the constructs. Composite constructs of PCL and chondrocyte-laden GelMA has not been made and characterised before. In our study cells were encapsulated in 20\% GeIMA and co-printed with the PCL strands, and channels were created by leaving $650 \mu \mathrm{m}$ space between the PCL and GelMA strands. The cell proliferation and ECM secretion were not affected by the multiple-material printing process when compared with the GelMA only structures. This study proves the concept of using a bioprinted composite construct that contains chondrocytes, GeIMA and PCL for making cartilaginous tissues. Future efforts will focus on fabricating constructs with anatomical shapes using this multi-material bioprinting approach and cartilage regeneration in animal models. The challenges for printing two materials into an anatomic shape mainly lie with the printer's software ability to define individual printing paths for multiple materials and the resolution of the printing (strut diameter). In addition, the complexity of an anatomical shape also plays an important role, particularly for extrusion printing where a filament is laid down to form shapes. Moreover, the printing resolution (diameter of struts) needs to be high (small struts) to allow precise deposition of multiple materials in a nose-shaped scaffold which is a thin structure. Currently, the diameter of GelMA struts is in the range of hundreds of microns. These challenges will need to be addressed by the combined force of 3D printer manufacturers and users in the future.

\section{Conclusions}

This study investigated the feasibility of using multi-material 3D bioprinting to create cell-laden and mechanically enhanced constructs that can potentially be used for major nasal reconstruction. The hydrogel GeIMA was used as a cell carrier and was successfully printed without the need of viscosity enhancers or supportive moulds. This was achieved by using the thermo-reversible properties of GelMa that showed a suitable viscosity range for extrusion printing at the temperatures of $15^{\circ} \mathrm{C}$ and $20^{\circ} \mathrm{C}$. A detailed assessment on the effects of $3 \mathrm{D}$ printing conditions on the viability and genotoxicity of chondrocytes was also performed. This assessment revealed that prolonged UV exposure and 
extrusion had the largest negative effects on cell viability. Based on the rheology data and the cell responses during in vitro culture of the bioprinted chondrocyte-laden GelMA constructs, it was found that $20 \%$ GelMA was the optimal concentration to be used in terms of printability and cell functionality. Cell-laden GelMA hydrogels showed cell proliferation and cartilage ECM secretion. However, the mechanical properties of the constructs were lower than septal cartilage. Therefore, a multi-material approach was adopted to fabricate cell-laden GelMA-PCL porous composite structures. This work shows for the first time the printing of porous multi-material GeIMA-PCL constructs without viscosity enhancers, sacrificial materials or supportive moulds that need removal after printing. The cell proliferation and secretion of cartilage-specific ECM in these composite constructs were similar to those in pure cell-laden GelMA constructs, suggesting the combination of materials did not interfere with the behaviours of chondrocytes.

\section{Acknowledgments}

We thank CONACYT Mexico for sponsoring the studentship for Laura Ruiz-Cantu.

\section{References}

[1] A. Borges, J. Fink, P. Villablanca, R. Eversole, R. Lufkin, Midline destructive lesions of the sinonasal tract: Simplified terminology based on histopathologic criteria, Am. J. Neuroradiol. 21 (2000) 331-336. doi:10696019.

[2] J.B. Watelet, P. Van Cauwenberge, Applied anatomy and physiology of the nose and paranasal sinuses., Allergy. 54 Suppl 5 (1999) 14-25.

[3] F.J. Menick, Nasal reconstruction with a forehead flap., Clin. Plast. Surg. 36 (2009) 443-59. doi:10.1016/j.cps.2009.02.015.

[4] S.B. Cannady, T. a Cook, M.K. Wax, The total nasal defect and reconstruction., Facial Plast. Surg. Clin. North Am. 17 (2009) 189-201. doi:10.1016/j.fsc.2009.01.002.

[5] Y. Cao, J.P. Vacanti, K.T. Paige, J. Upton, C.A. Vacanti, Transplantation of Chondrocytes Utilizing a Polymer-Cell Construct to Produce Tissue Engineered Cartilage in the Shape of a Human Ear, Plast. Reconstr. Surg. (1997) 304-304.

[6] S.J. Shieh, S. Terada, J.P. Vacanti, Tissue engineering auricular reconstruction: In vitro and in vivo studies, Biomaterials. 25 (2004) 1545-1557. doi:10.1016/S0142-9612(03)00501-5.

[7] N. Isogai, T. Morotomi, S. Hayakawa, H. Munakata, Y. Tabata, Y. Ikada, H. Kamiishi, Combined chondrocyte-copolymer implantation with slow release of basic fibroblast growth factor for tissue engineering an auricular cartilage construct, J. Biomed. Mater. Res. - Part A. 
74 (2005) 408-418. doi:10.1002/jbm.a.30343.

[8] S.H. Kamil, K. Kojima, M.P. Vacanti, L.J. Bonassar, C.A. Vacanti, R.D. Eavey, In vitro tissue engineering to generate a human-sized auricle and nasal tip, Laryngoscope. 113 (2003) 9094. doi:10.1097/00005537-200301000-00017.

[9] I. Fulco, S. Miot, M.D. Haug, A. Barbero, A. Wixmerten, S. Feliciano, F. Wolf, G. Jundt, A. Marsano, J. Farhadi, M. Heberer, M. Jakob, D.J. Schaefer, I. Martin, Engineered autologous cartilage tissue for nasal reconstruction after tumour resection: an observational first-inhuman trial., Lancet (London, England). 384 (2014) 337-46. doi:10.1016/S01406736(14)60544-4.

[10] M. Kesti, C. Eberhardt, G. Pagliccia, D. Kenkel, D. Grande, A. Boss, M. Zenobi-Wong, Bioprinting Complex Cartilaginous Structures with Clinically Compliant Biomaterials, Adv. Funct. Mater. (2015) 7406-7417. doi:10.1002/adfm.201503423.

[11] H.-W. Kang, S.J. Lee, I.K. Ko, C. Kengla, J.J. Yoo, A. Atala, A 3D bioprinting system to produce human-scale tissue constructs with structural integrity, Nat. Biotechnol. 34 (2016) 312-319. doi:10.1038/nbt.3413.

[12] J. Visser, B. Peters, T.J. Burger, J. Boomstra, W.J.A. Dhert, F.P.W. Melchels, J. Malda, Biofabrication of multi-material anatomically shaped tissue constructs, Biofabrication. 5 (2013) 035007. doi:10.1088/1758-5082/5/3/035007.

[13] J.-H. Shim, J.-S. Lee, J.Y. Kim, D.-W. Cho, Bioprinting of a mechanically enhanced threedimensional dual cell-laden construct for osteochondral tissue engineering using a multi-head tissue/organ building system, J. Micromechanics Microengineering. 22 (2012) 085014. doi:10.1088/0960-1317/22/8/085014.

[14] F. Pati, J. Jang, D.-H. Ha, S. Won Kim, J.-W. Rhie, J.-H. Shim, D.-H. Kim, D.-W. Cho, Printing three-dimensional tissue analogues with decellularized extracellular matrix bioink., Nat. Commun. 5 (2014) 3935. doi:10.1038/ncomms4935.

[15] L. Ruiz-Cantu, A. Gleadall, C. Faris, J. Segal, K. Shakesheff, J. Yang, Characterisation of the surface structure of $3 D$ printed scaffolds for cell infiltration and surgical suturing, Biofabrication. 8 (2016). doi:10.1088/1758-5090/8/1/015016.

[16] A.I. Van Den Bulcke, B. Bogdanov, N. De Rooze, E.H. Schacht, M. Cornelissen, H. Berghmans, Structural and Rheological Properties of Methacrylamide Modified Gelatin Hydrogels, Biomacromolecules. 1 (2000) 31-38. doi:10.1021/bm990017d.

[17] K. Yue, G. Trujillo-de Santiago, M.M. Alvarez, A. Tamayol, N. Annabi, A. Khademhosseini, Synthesis, properties, and biomedical applications of gelatin methacryloyl (GeIMA) hydrogels, Biomaterials. 73 (2015) 254-271. doi:10.1016/j.biomaterials.2015.08.045. 
[18] B.J. Klotz, D. Gawlitta, A.J.W.P. Rosenberg, J. Malda, F.P.W. Melchels, Gelatin-Methacryloyl Hydrogels: Towards Biofabrication-Based Tissue Repair, Trends Biotechnol. 34 (2016) 394407. doi:10.1016/j.tibtech.2016.01.002.

[19] W. Schuurman, P. a Levett, M.W. Pot, P.R. van Weeren, W.J. a Dhert, D.W. Hutmacher, F.P.W. Melchels, T.J. Klein, J. Malda, Gelatin-methacrylamide hydrogels as potential biomaterials for fabrication of tissue-engineered cartilage constructs., Macromol. Biosci. 13 (2013) 551-61. doi:10.1002/mabi.201200471.

[20] D. Kumar, I. Gerges, M. Tamplenizza, C. Lenardi, N.R. Forsyth, Y. Liu, Three-dimensional hypoxic culture of human mesenchymal stem cells encapsulated in a photocurable, biodegradable polymer hydrogel: A potential injectable cellular product for nucleus pulposus regeneration, Acta Biomater. 10 (2014) 3463-3474. doi:10.1016/j.actbio.2014.04.027.

[21] T. Billiet, M. Vandenhaute, J. Schelfhout, S. Van Vlierberghe, P. Dubruel, A review of trends and limitations in hydrogel-rapid prototyping for tissue engineering., Biomaterials. 33 (2012) 6020-41. doi:10.1016/j.biomaterials.2012.04.050.

[22] A. Panwar, L.P. Tan, Current status of bioinks for micro-extrusion-based 3D bioprinting, Molecules. 21 (2016). doi:10.3390/molecules21060685.

[23] J. Malda, J. Visser, F.P. Melchels, T. Jüngst, W.E. Hennink, W.J. a Dhert, J. Groll, D.W. Hutmacher, 25th anniversary article: Engineering hydrogels for biofabrication., Adv. Mater. 25 (2013) 5011-28. doi:10.1002/adma.201302042.

[24] J. Wang, Y. Wei, S. Zhao, Y. Zhou, W. He, Y. Zhang, W. Deng, The analysis of viability for mammalian cells treated at different temperatures and its application in cell shipment, (2017) $1-16$.

[25] V.H.M. Mouser, F.P.W. Melchels, J. Visser, W.J.A. Dhert, D. Gawlitta, J. Malda, Yield stress determines bioprintability of hydrogels based on gelatin-methacryloyl and gellan gum for cartilage bioprinting., Biofabrication. 8 (2016) 035003. doi:10.1088/1758-5090/8/3/035003.

[26] K. Nair, M. Gandhi, S. Khalil, K.C. Yan, M. Marcolongo, K. Barbee, W. Sun, Characterization of cell viability during bioprinting processes, Biotechnol. J. 4 (2009) 1168-1177. doi:10.1002/biot.200900004.

[27] T. Billiet, E. Gevaert, T. De Schryver, M. Cornelissen, P. Dubruel, The 3D printing of gelatin methacrylamide cell-laden tissue-engineered constructs with high cell viability., Biomaterials. 35 (2014) 49-62. doi:10.1016/j.biomaterials.2013.09.078.

[28] W. Liu, M.A. Heinrich, Y. Zhou, A. Akpek, N. Hu, X. Liu, X. Guan, Z. Zhong, X. Jin, A. Khademhosseini, Y.S. Zhang, Extrusion Bioprinting of Shear-Thinning Gelatin Methacryloyl Bioinks, Adv. Healthc. Mater. 6 (2017) 1-11. doi:10.1002/adhm.201601451. 
[29] Z. Liu, H. Chen, H. Yang, J. Liang, X. Li, Low-dose UVA radiation-induced adaptive response in cultured human dermal fibroblasts, Int. J. Photoenergy. 2012 (2012). doi:10.1155/2012/167425.

[30] T. Vermonden, N.E. Fedorovich, D. van Geemen, J. Alblas, C.F. van Nostrum, W.J.A. Dhert, W.E. Hennink, Photopolymerized thermosensitive hydrogels: Synthesis, degradation, and cytocompatibility, Biomacromolecules. 9 (2008) 919-926. doi:10.1021/bm7013075.

[31] E.E. Coates, C.N. Riggin, J.P. Fisher, Photocrosslinked alginate with hyaluronic acid hydrogels as vehicles for mesenchymal stem cell encapsulation and chondrogenesis., J. Biomed. Mater. Res. A. 101 (2013) 1962-70. doi:10.1002/jbm.a.34499.

[32] I. Mironi-Harpaz, D.Y. Wang, S. Venkatraman, D. Seliktar, Photopolymerization of cellencapsulating hydrogels: Crosslinking efficiency versus cytotoxicity, Acta Biomater. 8 (2012) 1838-1848. doi:10.1016/j.actbio.2011.12.034.

[33] A.D. Rouillard, C.M. Berglund, J.Y. Lee, W.J. Polacheck, Y. Tsui, L.J. Bonassar, B.J. Kirby, Methods for photocrosslinking alginate hydrogel scaffolds with high cell viability, Tissue Eng. - Part C Methods. 17 (2011) 173-179. doi:10.1089/ten.tec.2009.0582.

[34] M. Ulrich-Vinther, M.D. Maloney, J.J. Goater, K. Søballe, M.B. Goldring, R.J. O’Keefe, E.M. Schwarz, Light-activated gene transduction enhances adeno-associated virus vectormediated gene expression in human articular chondrocytes, Arthritis Rheum. 46 (2002) 20952104. doi:10.1002/art.10433.

[35] T.R. Dunkern, G. Fritz, B. Kaina, Ultraviolet light-induced DNA damage triggers apoptosis in nucleotide excision repair-de ${ }^{\circledR}$ cient cells via Bcl-2 decline and caspase- 3 / - 8 activation, (2001) 6026-6038.

[36] a. Kinner, W. Wu, C. Staudt, G. Iliakis, -H2AX in recognition and signaling of DNA doublestrand breaks in the context of chromatin, Nucleic Acids Res. 36 (2008) 5678-5694. doi:10.1093/nar/gkn550.

[37] J. Rouwkema, B.F.J.M. Koopman, C.A.V. Blitterswijk, W.J.A. Dhert, J. Malda, Supply of nutrients to cells in engineered tissues, Biotechnol. Genet. Eng. Rev. 26 (2009) 163-178. doi:10.5661/bger-26-163.

[38] S. Ashraf, B.H. Cha, J.S. Kim, J. Ahn, I. Han, H. Park, S.H. Lee, Regulation of senescence associated signaling mechanisms in chondrocytes for cartilage tissue regeneration, Osteoarthr. Cartil. 24 (2016) 196-205. doi:10.1016/j.joca.2015.07.008.

[39] S. Kobayashi, A. Meir, J. Urban, Effect of cell density on the rate of glycosaminoglycan accumulation by disc and cartilage cells in vitro, J. Orthop. Res. 26 (2008) 493-503. doi:10.1002/jor.20507. 
[40] A.R. Gannon, T. Nagel, A.P. Bell, N.C. Avery, D.J. Kelly, Postnatal changes to the mechanical properties of articular cartilage are driven by the evolution of its Collagen network, Eur. Cells Mater. 29 (2015) 105-123. doi:10.22203/eCM.v029a09.

[41] J.P. Caffrey, M. , Anton M. Kushnaryov, V., Marsha S. Reuther, R.L.S. W. Wong, Kristen K. Briggs,, Koichi Masuda, and D. Watson, Flexural Properties of Native and Tissue Engineered Human Septal Cartilage, Otolaryngol Head Neck Surg. 4 (2013) 576-581. doi:10.1126/scisignal.2001449.Engineering.

[42] M.F. Griffin, Y. Premakumar, A.M. Seifalian, M. Szarko, P.E.M. Butler, Biomechanical characterisation of the human nasal cartilages; implications for tissue engineering, J. Mater. Sci. Mater. Med. 27 (2016) 1-6. doi:10.1007/s10856-015-5619-8.

[43] X. Hu, L. Ma, C. Wang, C. Gao, Gelatin hydrogel prepared by photo-initiated polymerization and loaded with TGF- $\beta 1$ for cartilage tissue engineering, Macromol. Biosci. 9 (2009) 11941201. doi:10.1002/mabi.200900275.

[44] J. Visser, D. Gawlitta, K.E.M. Benders, S.M.H. Toma, B. Pouran, P.R. van Weeren, W.J.A. Dhert, J. Malda, Endochondral bone formation in gelatin methacrylamide hydrogel with embedded cartilage-derived matrix particles, Biomaterials. 37 (2015) 174-182. doi:10.1016/j.biomaterials.2014.10.020.

[45] X. Li, S. Chen, J. Li, X. Wang, J. Zhang, N. Kawazoe, G. Chen, 3D Culture of Chondrocytes in Gelatin Hydrogels with Different Stiffness, Polym. . 8 (2016). doi:10.3390/polym8080269. 